\title{
Ways to create an effective positioning of Romanian universities through identity, image and promotion elements
}

\author{
Marius BĂLĂȘESCU \\ Transilvania University, Brașov, Romania \\ mariusbalasescu@unitbv.ro \\ Simona BĂLĂȘESCU \\ Transilvania University, Brașov, Romania \\ simonabalasescu@unitbv.ro
}

\begin{abstract}
The process of universities positioning, as a component of educational and university marketing consists of a synergetic system composed of all the marketing and management efforts of a university as an entity inside the educational market, materialized in identity, image and promotion elements that lead to the creation of a strong brand of the university and to contribute to the consolidation of a solid reputation. The present paper aims to address the topic of effective positioning of universities, as a tool of university marketing, in a Romanian and European higher education market with increasingly complex evolutions. Taking into account the tendencies in the field of education and university marketing (eg: competition between universities in Romania, but also at European and worldwide level), the authors consider that higher education institutions have to emphasize the various elements of identity, image and institutional promotion, because current or future bachelor students, master students and PhD students want to belong to some entities with prestige and reputation, in other words, with a strong image and identity to provide them with confidence and security. The paper considers an approach on three main components: the analysis of the stage of knowledge of the higher education field, an original marketing research research and the conclusions and solutions. The research consists of a quantitative marketing research applied among the Romanian high school graduating students, regarding their perception about different elements of identity, image and promotion of some important universities in Romania. The paper aims, as a fundamental objective, to provide results that can be integrated into the marketing strategies of the universities from Romania and Europe.
\end{abstract}

Keywords: educational marketing, university marketing, brand of the university, institutional identity, institutional image, higher education.

\section{Introduction}

The companies are in continuous development, as are the requirements of the population regarding the goods and services made available. That's why offers are becoming ever more diversified and more individualized to cope with the wave of demands. Educational institutions face a growing need to differentiate themselves on the competitive market. Thus, educational marketing can be considered as a process of integrating marketing into education. Until the 1980s, the need for marketing was not felt by the education institutions, their activity being based on the product only, thus capitalizing on the potential of the offer, without involving significant efforts to attract candidates.

With the growth of types of institutions, the diversification of supply and the promotion of the new entrepreneurial and autonomous managerial model, the importance of marketing activity moves from supply to demand, from product focus to consumer focus. 
In the academic environment, the concept of marketing acquires the same valences as in the business environment, contributing to institutional development. Nowadays, we are witnessing the intensification of competition between universities to attract the best students and the most enlightened minds to become students. At the same time, it is remarkable that universities are very similar to the business world. Market power is replaced by a better quotation of publications that have become a global business, as higher education institutions spend colossal sums to access the most prestigious reviews. Thus, many marketing strategies used by the business world are taken over by higher education institutions to get a better quote in the top universities.

Brands are powerful entities because they combine rational values (based on product performance) with emotional values. (De Chernatonz, 2010)

Like any consumer behavior, the choice of the university is determined by both rational and emotional factors. Rational influences include career prospects, emotional factors are those that are more subjective or more sociologically substantiated. (Bratianu \& Orzea, 2013; Winter \&Chapleo, 2015).

The way the brand manages to communicate with current or potential consumers plays an important role. Their perception of commercial messages and skeptical attitude is a real challenge. (Nechita, 2012).

From the context of educational services, it is considered that the service environment or physical environment has a significant influence on consumer perception of service quality.( Goi Mei-Teh \& Kalidas, 2015).

The paper considers an approach on three main components: the analysis of the stage of knowledge of the higher education field, an original marketing research and the conclusions and solutions. The research consists of a quantitative marketing research applied among the Romanian high school graduating students, regarding their perception about different elements of identity, image and promotion of some important universities in Romania.

\section{Literature review}

\section{The evolution and importance of educational marketing}

The application of marketing in the field of educational services is known as educational marketing. The necessity of approaching the educational activity in a marketing optic is determined by the similarities with the economic activities in the field of service provision.(Olteanu, 2007)

From the same perspective, Kotler and Fox define the educational marketing process as an analysis, planning, implementation, and control of the planned training, capable of bringing about voluntary changes of values in line with market targets in such a way as to achieve objectives of the institutions. (Kotler \& Fox, 1995) In the authors' view, educational marketing involves designing institutional offers to meet the needs and desires identified on the market and effective use of communication, price and distribution to inform, motivate and serve the market. They show three steps in the development of educational marketing: "marketing is not necessary", "marketing as a promotion" and "marketing as positioning".

The concept of market orientation or the marketing concept is based on the premise that the achievement of the goals of the organization depends on the anticipated knowledge of the needs, requirements and desires of consumers, generally target markets, and the concern to satisfy them at a higher level than that of competitors. Market orientation or 
marketing orientation is based on the philosophy of meeting consumer requirements by identifying and getting to know them as accurately as possible. In this situation, the profile will depend on the level of satisfaction of the wishes and preferences of consumers. (Lefter et al.,2000)

The stage called "marketing is not necessary" highlights the fact that the value of education is visible without the need for promotion, and those who want education will inevitably enroll in school. It is also surprising that the Curriculum changes very rarely over time, and its value has a history. Thus, the school was considered an archive, and candidates were either for what they were offering, or because there were no other alternatives.

The second stage, entitled "marketing as a promotion" has its starting point in recruitment and later admission. Schools have noticed that they do not have enough candidates, leading to a stronger focus on advertising.

"Marketing as Positioning" is the third stage and highlights the awareness of the importance of differentiation among educational institutions. They understood that, in order to be a good competitor on the market, they must highlight their history, distinctive features and opportunities. Thus, by positioning it is meant, distinguishing the institutions of competitors by some significant dimensions for the candidates. The objectives of the positioning are to highlight the real differences of the institutions compared to others so that they can best meet the needs of current and future candidates.

\section{University marketing - part of educational marketing}

In view of globalization, higher education is considered to be a powerful engine that drives the development process at national and international level through a significant contribution to the well functioning of society, the solution for growth and development of national economies, both in developed and developing countries.

Based on current social and economic developments, universities are becoming more aware of their responsibility in the training of specialists in all areas of activity, so attracting and retaining valuable students must become the main purpose of university marketing. (Herrero-Crespo et al.,2016)

Higher education institutions traditionally had the image of institutions independent of political or social influences, an image that was built on the basis of the quality of educational programs, research results, and academic names of teachers with complete experience and not based on the elements of advertising or brand. Over time, however, the choices of young people in university studies have increasingly relied on the reputation of universities and their image, progressively outlining the idea of university branding, based on the name, logo, message and other promotional aspects that positioned the institution higher education and highlighted it in competition. (Bratianu \& Bejinaru, 2017; Ilies \& Fărcaș, 2008)

The image of an organization is made up of four elements that are closely linked to each other. These elements are: personality, reputation, values and identity.(Harrison, 1995)

Branding has a recent development in higher education and is strongly associated with the notion of organizational reputation. When branding principles are applied in higher education, we gain appreciation for how important brand recognition is in attracting customer attention. (Yu-Chuan Chen, 2015)

The brand shows consumers the origin of the products or services and gives them a certain degree of confidence about their quality and benefits. Referring both to the essential 
aspects and the concept of brand value to consumers and their holding companies, Clifton Maughan offers the following definition: "a mixture of tangible and non-intangible attributes, symbolized by a trademark, and which, if properly managed, creates influence and generates value". (Clifton and Maughan, 2000).

Identity is a basic concept in the existence of a brand, because it makes it unique. While the brand appears on the market it is accompanied by its identity. Identity is what we want to express through the brand. Today, not all organizations take into account the true sense of their identity, but even if they do not recognize it, identity is always present. Identity elements, such as brand name, logo, URLs (Uniform Resource Locator or Uniform Resource Locating Address - used in www.), Graphic symbols, characters, slogans, packaging, product or package shapes, sounds or even smells, tastes and tactile signs are part of the brand identity that can be registered. (Bicu, 2007)

The reputation of a university is considered as an important branding factor in relation to other aspects. This indicates that reputation built over the years may be the strongest branding advantage for a university. As such, any branding effort of a university should focus on the brand name, the high standard of education, the quality of the courses and the institutional experience, which are the variables of the reputation indicator. (Perera et al., 2016)

We believe that a key element in a university branding strategy is the visual identity manual. This is a document that contains some clear and detailed directions about how the brand's visual identity can be used in internal and external communication processes.

The role of the identity manual is to prevent mistakes of the visual identity elements of the brand on various printed or digital materials, both in terms of dimensions, proportions and graphics and chromatic components. Also, the identity manual has the function of ensuring coherent visual communication, which is why the information should be as explicit as possible. The elements that are part of this document are: the essence of the brand or its invisible side that helps to understand the arguments behind the design choices: color, shape, symbols, logo and slogan, as well as ways of using them, the color palette . In an identity manual, typography should be displayed: what families of fonts can be used, what size, line height, kerning value, whether or not a certain format is tolerated, and so on. In addition, where there are variations, it specifies which fonts should be used in online and offline media, titles, or text. The university website is also the fastest and most readily available source of information on the educational offerings offered, which is why it needs to be continuously updated and structured so that information is easy to find.

One way that should be further emphasized by universities is storytelling that helps to establish and unveil a culture of the organization and illustrate the brand universe. Storytelling is a means of building a culture of the organization, a means of action and one of mobilizing emotions through common stories. Storytelling is the presentation of a brand in a narrative form as a story. It is a content that puts into play its brand or its universe. The concept of storytelling in organizations covers several phenomena. First, it is an observable one in every organization: sharing stories in the form of narratives and more globally, the organization becomes the place where the narratives are produced. (State, 2016).

\section{Methodology}

In order to achieve the article's objectives, a quantitative market research was conducted. The period in which this study was made is December 2017 - February 2018. 
Data collection was based on a questionnaire which includes 18 questions which was sent online to respondents, because the costs are lower and the time of data collection is short. Through this research it is desired to find out the opinions and attitudes of the students of Braşov regarding the image of higher education institutions in Romania. We specify that a total of 104 students answered this questionnaire. According to the list of Braşov pupils from the 12th grade, provided by the School Inspectorate of Braşov, the number of pupils in Brasov from the terminal classes is 5587 in the analyzed year.

The sampling method used in this research is non-aleatory on a voluntary basis. So the questionnaire was published in various online groups with 12th grade students in the high schools in Braşov, and they, according to time and availability, completed the questionnaire. The criterion for the selection of the sample was that all respondents were pupils in high school grades in the high schools in Braşov. For this research, we have selected 5 universities in Romania, namely: Babeş Bolyai University of Cluj Napoca, Lucian Blaga University of Sibiu, University of West Timişoara, University of Bucharest and Transilvania University of Brasov.

The objectives of marketing research concern three major aspects: identifying how the university logo affects students, identifying how the slogan of universities influences students and determining the importance of campaigns to promote high school universities.

In view of the above mentioned aspects, the following objectives were formulated: Determining the level of recognition of the logos presented; Identifying the level of recognition of the intended logos; Identifying the importance of colors in the construction of a logo; Identifying the importance of the slogan among students; Determining the attractiveness of a particular slogan; Establishing student identification with one of the slogans presented; Identifying impressions about the regularity of campaigns promoting universities in high schools; Identifying views on university promotion campaigns

After information collection with the help of the questionnaire, the data statistical processing was made with the SPSS system (Statistical Package for Social Sciences). The first stage was to define the relevant variables of the research. After that, the answer options were coded for facilitating data introduction in the computer. Coding was achieved depending on each question and the scale used for that question. SPSS database was filled in after the introduction of all questionnaires, and finally, data was centralized as frequency tables and graphs (Constantin, 2012)

\section{Results and discussions}

The research has shown a lot of information, further being presented the most relevant for the issues taken into account. When asked about the desire to study at a faculty, $7.7 \%$ of all students questioned answered that they did not want to join a college and $92.3 \%$ of all the students questioned answered that they wanted to register to a faculty. (Table 1).

Table 1. Do you want to study at a college?

\begin{tabular}{|c|c|c|c|c|c|}
\hline & & Frequency & Percent & Valid Percent & Cumulative Percent \\
\hline & Yes & 8 & 7.7 & 7.7 & 7.7 \\
\hline Valid & Not & 96 & 92.3 & 92.3 & 100.0 \\
\hline & Total & 104 & 100.0 & 100.0 & \\
\hline
\end{tabular}

Source: Authors' own research. 
Of the 96 students who answered this question I noticed that $40.6 \%$ want to attend a university in Brasov, 22.9\% want to enroll in a university in Cluj Napoca, 21.9\% want to follow a faculty in Bucharest, $10.4 \%$ want to enroll in a college in Sibiu, 3.1\% want to enroll in a college in Timisoara, $1 \%$ want to attend a college in Bacau. (Table 2)

Table 2. In which city do you want to study at a college?

\begin{tabular}{|c|c|c|c|c|c|}
\hline \multicolumn{2}{|l|}{10} & \multirow{2}{*}{\begin{tabular}{|l|} 
Frequency \\
1 \\
\end{tabular}} & \multirow{2}{*}{\begin{tabular}{|l|} 
Percent \\
1.0 \\
\end{tabular}} & \multirow{2}{*}{\begin{tabular}{|l|} 
Valid Percent \\
1.0 \\
\end{tabular}} & \multirow{2}{*}{\begin{tabular}{|l|} 
Cumulative Percent \\
1.0 \\
\end{tabular}} \\
\hline \multirow{7}{*}{ Valid } & Bacau & & & & \\
\hline & Brasov & 39 & 37.5 & 40.6 & 41.7 \\
\hline & Bucuresti & 21 & 20.2 & 21.9 & 63.5 \\
\hline & Cluj Napoca & 22 & 21.2 & 22.9 & 86.5 \\
\hline & Sibiu & 10 & 9.6 & 10.4 & 96.9 \\
\hline & Timisoara & 3 & 2.9 & 3.1 & 100.0 \\
\hline & Total & 96 & 92.3 & 100.0 & \\
\hline Missing & 88 & 8 & 7.7 & & \\
\hline Total & & 104 & 100.0 & & \\
\hline
\end{tabular}

Source: Authors' own research

From the data analysis, it results that Babes Bolyai University's logo is the most wellknown by the students questioned. Of the total of $100 \%$, the logo of the Babes Bolyai University in Cluj was recognized by $31.8 \%$ of the respondents. The 2 nd place is the logo of Transilvania University, 3rd place, Lucian Blaga University, 4th place, University of Bucharest and on 5th place, West University of Timisoara. (Table 3)

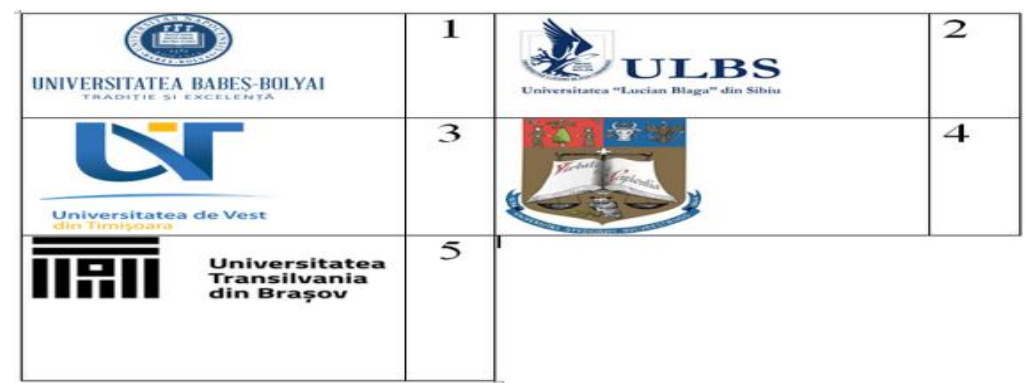

Figure 1. University logo

Table 3. Tick the logs you've seen so far

\begin{tabular}{|l|l|l|l|}
\hline & \multicolumn{2}{|l|}{ Responses } & Percent of \\
\cline { 2 - 4 } & $\mathbf{N}$ & Percent & cases \\
\hline The logo of the Babes Bolyai University has been recognized & 74 & $31,8 \%$ & $72,5 \%$ \\
\hline The logo of the Lucian Blaga University has been recognized & 41 & $17,6 \%$ & $40,2 \%$ \\
\hline The logo of the West University has been recognized & 33 & $14,2 \%$ & $32,4 \%$ \\
\hline The logo of the Bucharest University has been recognized & 38 & $16,3 \%$ & $37,3 \%$ \\
\hline $\begin{array}{l}\text { The logo of the Transilvania University of Brasov has been } \\
\text { recognized }\end{array}$ & 44 & $20,2 \%$ & $46,1 \%$ \\
\hline Total & $\mathbf{2 3 3}$ & $\mathbf{1 0 0 , 0} \%$ & $\mathbf{2 2 8 , 4 \%}$ \\
\hline
\end{tabular}

Source: Authors' own research

The question about the impact of the slogan of each university on the motivation to choose a certain university center, the most suggestive slogan with a number of 32 positive answers (30.8\%) is the one of Lucian Blaga University of Sibiu "A thousand identities, one 
university. Second place is the slogan "Learn to be in the center" of Transilvania University with 29 positive responses (27.9\%). 3rd place was the slogan "Culture and discovery" of Bucharest University with 28 positive responses $(26.9 \%)$. On the 4th place the slogan "Traditio nostra unacum Europae virtutibus splendet!" by Babes Bolyai with 12 positive responses $(11.5 \%)$. The last place is the Western University slogan with 3 positive responses (2.9\%). (Table 4).

Table 4. Which of the following slogans do you find the most motivating for you as a future student?

\begin{tabular}{|c|c|c|c|}
\hline & \multicolumn{2}{|c|}{ Responses } & \multirow{2}{*}{$\begin{array}{l}\text { Percent of } \\
\text { Cases }\end{array}$} \\
\hline & $\mathbf{N}$ & Percent & \\
\hline "Learn to be in the center" & 29 & $27,9 \%$ & $28,2 \%$ \\
\hline "A thousand identities, one university" & 32 & $30,8 \%$ & $31,1 \%$ \\
\hline "Culture and discovery" & 28 & $26,9 \%$ & $27,2 \%$ \\
\hline "Traditio nostra unacum Europe virtutibus splendet & 12 & $11,5 \%$ & 11,7 \\
\hline "Non scholae, sed vitae discimus!" & 3 & $2,9 \%$ & $2,9 \%$ \\
\hline Total & 104 & $100,0 \%$ & $101,0 \%$ \\
\hline
\end{tabular}

Following the ordering of the criteria that influence the choice of the educational institution, the respondents stated that the most influential criterion for the respondents in the choice of the educational institution is that related to the reputation of that institution (Table 5)

Table 5. Order the following criteria that will influence your choice of the educational institution according to their importance, the 1st place being the most important criterion.

\begin{tabular}{|l|c|c|c|}
\hline & N & Mean & Std. Deviation \\
\hline $\begin{array}{l}\text { The place that "reputation" occupies as an aspect } \\
\text { in choosing the university education institution }\end{array}$ & 104 & 1.8173 & .85632 \\
\hline $\begin{array}{l}\text { The place that "location" occupies as a look } \\
\text { in choosing the university education institution }\end{array}$ & 104 & 2.0577 & .78613 \\
\hline $\begin{array}{l}\text { The place that "endowment" occupies as a look } \\
\text { in choosing a university education institution }\end{array}$ & 104 & 2.1250 & .78441 \\
\hline Valid N (listwise) & $\mathbf{1 0 4}$ & & \\
\hline
\end{tabular}

Source: Authors' own research

After testing the link between the type of questioned students and the degree of access to the site of Transilvania University in Brasov, we have the following information: (Table 6)

Table 6. Testing the link between the gender of questioned persones and accessing the site of Transilvania University in Brasov

\begin{tabular}{|l|l|l|l|}
\hline \multirow{2}{*}{ Gender } & \multicolumn{2}{|l|}{$\begin{array}{l}\text { Did you visit the site of Transilvania University } \\
\text { of Brasov? }\end{array}$} & \multirow{2}{*}{ Total } \\
\cline { 2 - 4 } & DA & NU & \\
\hline Male & 25 & 21 & 46 \\
\hline Female & 32 & 26 & 58 \\
\hline Total & $\mathbf{5 7}$ & $\mathbf{4 7}$ & $\mathbf{1 0 4}$ \\
\hline
\end{tabular}


We observe that a number of 32 female respondents have accessed the site of Transylvania University in Brasov so far and a number of 25 male respondents have accessed the site of Transilvania University in Brasov.

\section{Conclusion}

In view of current social and economic developments, universities are becoming more and more aware of the importance of marketing, thus trying to develop continuously on this side. Their main purpose is to attract and retain valuable students.

Quality in higher education is the solution of performance and excellence, as it calls for ongoing efforts and involvement from the institutions. The biggest challenge for a higher education institution is to become a source of satisfaction for the student, quality being the one that holds the balance between internal and external forces

As a result of the research, the elements of identity and image are very important factors of influence of the respondents in the choice of university institutions. We note that reputation is the most influential factor in choosing a higher education institution. A solid reputation is characterized both by the results obtained annually by the institutions, but also by the elements of image and identity, such as: slogan, logo, endowments, elements that differentiate it from the other competing institutions and give it uniqueness.

Also, the results of marketing research show that less than $30 \%$ of the surveyed students were involved in university promotion activities, whether it is simply informing about educational offers or whether it is more like how be visiting a faculty in order to learn the story of that faculty and get acquainted with it. Aspects such as the distance between home and university are not an impediment for survey respondents, as long as the university they are studying has a strong reputation, set of well-established values, and of course a certainty in terms of offering a job in the respective field, at the end of the studies

Based on the researched aspects regarding the positioning of the educational institutions on the Romanian market we have the following proposals:

More focus is needed on the target audience, whether we are talking about prospective students or whether we are talking about maintaining students. When we say a greater focus on the target audience, we mean, first of all, better communication with them to give them safety, but also satisfaction that they have made the best choice.

Another suggestion is to encourage universities to participate and organize as many promotional items as possible at national and international level, in order to achieve interaction between future candidates and institutions, to get in touch with the image of the institution and to recognize it through its defining elements.

Another important element is to inform, first of all, the current students of the institutions about the short history, the short story of their emergence and establishment, the university or the faculty they belong to. Thus, a story is outlined in a unique way that they can spread further. A story told in a special event, such as the day of that institution, because there is a big difference between being told in such a framework and published on the site.

\section{References}

Bicu, C. (2007). BRAND. From word to smell, Bucharest: Brand4Brands Press

Bratianu, C. \& Bejinaru, R. (2017). Knowledge strategies for increasing IC of universities. In Lopez, I.T. \& Serrasqueiro, R. (Eds.). Proceedings of the 9th European Conference on 
Intellectual Capital (pp. 34-42), Instituto Universitario de Lisboa (ISCTE), Portugal, 6-7 April 2017. Reading: Academic Conferences and Publishing International.

Bratianu, C. \& Orzea, I. (2013). Emotional knowledge: The hidden part of the knowledge iceberg. In Janiunaite, B., Pundziene, A. \& Petraite, M. (Eds.). Proceedings of the 14th European Conference on Knowledge Management (pp. 82-90), Kaunas University of Technology, Lithuania, 5-6 September 2013. Reading: Academic Conferences and Publishing International.

Chen, Yu-Chuan (2015): A Study of the Interrelationships Among Service Recovery, Relationship Quality, and Brand Image in Higher Education Industries, Asia-Pacific Edu Res, 24(1), 83 - 110

Clifton, R. \& Maughan, E.(2000). The future of Brand. London: Macmillan.

Costantin, C. (2012). Analiza datelor de marketing: aplicații în SPSS, C.H. Beck, Bucharest.

De Chernatonz, L.(2010). From Brand Vision to Brand Evaluation. The strategic Process of Growing and Strenghtening Brands, third edition. Oxford: Elsevier Ltd., pp. 56-57.

Goi Mei-Teh \& Kalidas, V., (2015): Effect of Servicescape on Emotion, Mood, and Experience among HEI students, World Review of Business Research, vol 9. No.20, 54 -55.

Harrison, S.(1995), Public Relation - An Introduction, London, Routledge.

Herrero-Crespo, Á., San Martín Gutiérrez, H., \& Garcia-Salmones, Maria del Mar (2016) University of Cantabria, Santander, Spain,: Influence of country image on country brand equity: application to higher education services, International Marketing Review Vol. 33 No. 5,124-125.

Ilies, V. \& Fărcaș, A.F., (2008). Rebranding of higher education in Romania, communication and public relations, Babeș-Bolyai, University of Cluj-Napoca, pp.175-176 Retrieved from: https://old.upm.ro/ldmd/LDMD-01/Cpr/Cpr\%2001\%2023.pdf

Kotler, Ph. \& Fox F.A., (1995). Strategic marketing for educational institutions, Englewood Cliffs, N.J : Prentice-Hall.

Lefter C., (Coordinator) Brătucu,G., Chițu, I., Răuță, C., \& Bălășescu, M., (2000) Marketing Vol I, Brasov: Transilvania University of Brasov Press.

Olteanu, V. (2007). Management Marketing, Bucharest: Ecomar Press.

Nechita, F. ( 2012) Constructia de marcă, Transilvania University of Brasov Press.

Perera, P., Abeysekera,N., \& Samarasinghe, D., (2016): Potential association of private university branding effots with perceptions and attitudes of prospective students: a study in Sri Lanka, Management\&Marketing, volume XIV, 171 - 201

State, A. M., (2016): Narrative Communication and Identity of University Branding, The Romanian Journal of Sociology, New series, nr. 3-4, pp. 319-320 Retrieved from: http://www.revistadesociologie.ro/sites/default/files/09-aastate.pdf

Winter,E. \& Chapleo, C., (2015): An exploration of the effect of servicescape on student institution choice in UK universities, University of the West of England, NO. 25. 90 - 93 